Meta

Journal des traducteurs

Translators' Journal

\title{
Il y a table et table
}

\section{Robert Dubuc}

Volume 14, numéro 2, juin 1969

URI : https://id.erudit.org/iderudit/002600ar

DOI : https://doi.org/10.7202/002600ar

Aller au sommaire du numéro

Éditeur(s)

Les Presses de l'Université de Montréal

\section{ISSN}

0026-0452 (imprimé)

1492-1421 (numérique)

Découvrir la revue

Citer cet article

Dubuc, R. (1969). Il y a table et table. Meta, 14(2), 101-102.

https://doi.org/10.7202/002600ar

Ce document est protégé par la loi sur le droit d'auteur. L'utilisation des services d'Érudit (y compris la reproduction) est assujettie à sa politique d'utilisation que vous pouvez consulter en ligne.

https://apropos.erudit.org/fr/usagers/politique-dutilisation/
Cet article est diffusé et préservé par Érudit.

Érudit est un consortium interuniversitaire sans but lucratif composé de l’Université de Montréal, l'Université Laval et l'Université du Québec à Montréal. Il a pour mission la promotion et la valorisation de la recherche. https://www.erudit.org/fr/ 


\section{PROBLÈMES ET SOLUTIONS}

\section{IL Y A TABLE ET TABLE}

On reproche souvent à la langue technique d'affectionner outre mesure les mots savants, formés de racines grecques ou latines. C'est le principal grief qu'on a fait aux expressions mécanoïde (hardware) et programmoïde (software), en informatique. Il faut reconnaître que les mots savants sont encombrants, surtout si on les compare aux expressions tirées de la langue courante. En radiotélévision, des mots comme grue (crane), girafe (giraffe), perche (boom) sont d'excellents exemples d'assimilation de mots courants par le vocabulaire technique. Imagés et simples, ces mots offrent l'avantage d'enlever à la langue technique son caractère ésotérique. L'usager de la langue commune peut alors plus facilement communiquer avec le technicien ou le savant. Il ne fait pas de doute qu'on soulagerait sensiblement la " jargonnite» des langages scientifiques en puisant davantage dans les ressources de la langue courante ou même dans les langues régionales.

En recourant aux provincialismes, si riches, si expressifs, la pédologie s'est donné un vocabulaire auquel l'amoureux de la langue française non seulement n'aura rien à reprocher mais plutôt pourra recourir. Il suffisait de connaître les parlers du Midi (aubuges), de la Lorraine (blancheterre), de la Picardie (foraine), de l'Ardenne (rièze), du Gard (gapan). ${ }^{1}$

En toute honnêteté, il faut reconnaître qu'il n'est pas toujours facile de trouver des solutions simples à des problèmes de terminologie complexes. Il ne faut d'ailleurs pas refuser à la technique et aux sciences le droit de se forger les outils verbaux dont elles ont besoin. Mais il y a aujourd'hui, en particulier dans les sciences humaines, un abus du jargon scientifique dont personne ne bénéficie. Si l'on peut à la rigueur fermer les yeux sur ergothérapeute (occupational therapist) et autres formations savantes, que faut-il penser de «l'incrément de la culture », des « micro-milieux » dotés « d'organes de micro-discussion», des «vecteurs latents de la culture $\gg^{2}$. Un retour à la simplicité marquerait un grand progrès. C'est le

1. R. Etiemble, le Jargon des sciences, Paris, Hermann, 1966, p. 66.

2. Abraham A. Moles, "La radio-télévision au service de la promotion socio-culturelle», Communications, 7 (1966), p. 2 sqq. 
moins qu'on puisse dire.

La radiotélévision et le cinéma ont abondamment puisé aux sources de la langue courante. À cet égard, il est intéressant de relever diverses utilisations du mot table.

À la frontière de la langue courante et de la langue technique, se trouve d'abord le complément «de table» qui se dit des modèles d'appareils qui n'ont pas de support en propre et qu'on peut placer sur une table. On a donc récepteur de table (table set), radio de table (table radio), téléviseur de table (table TV set) et électrophone de table (table record player). De même, on appelle micro de table (table microphone) le micro cul-de-jatte qu'on place sur la table devant un conférencier ou un annonceur.

Passant du micro à la caméra, on se trouve en présence d'un pied ou socle de table. Il s'agit d'un socle de caméra très bas qu'on nomme en anglais table tripod.

Toujours guidés par le mot table, nous voici à la régie (control room) du studio où le mot table se trouve en concurrence avec le mot pupitre. On trouve assez souvent table ou pupitre de mixage (mixing console or panel), de trucage (special effects), de bruitage (sound effects), etc. Si l'on veut être subtil, il y aurait moyen toutefois de faire une distinction entre les deux: pupitre s'appliquant plus proprement aux dispositifs placés sur un plan incliné et table aux dispositifs placés sur un plan horizontal.

Avant de quitter la régie, il convient de s'arrêter aux «tables tournantes ». Que les adeptes du spiritisme se détrompent, il n'est pas question ici de sciences occultes, mais tout simplement d'un anglicisme (turn-table). Les plateaux où l'on fait tourner les disques se nomment tourne-disques.

Enfin un dernier usage technique du mot table nous fera un peu sortir de la radiodiffusion, tout en nous laissant dans le domaine des télécommunications. C'est au vocabulaire du téléphone que ressortit l'expression table d'écoute (bugging device or monitoring desk). Il s'agit d'un dispositif qui permet de capter au passage une conversation téléphonique. Cette indiscrétion technique s'exprime en anglais au moyen du verbe to (wire) tap, qui a engendré dans la langue populaire les expressions: «tapper une conversation téléphonique », «tapper un téléphone ». Pour parler français, il faudrait dire: capter clandestinement une conversation téléphonique; brancher une table d'écoute sur un téléphone; les conversations téléphoniques sont surveillées, etc. Ce n'est guère plus discret, mais c'est grammaticalement plus correct.

ROBERT DUBUC 